\title{
Parents' Perceptions of the Risk of Child Sexual Abuse and Their Protective Behaviors: Findings From a Qualitative Study
}

\section{Mary Elizabeth Collins University of Michigan}

This study examined parents' perceptions of the risk of child sexual abuse and self-reported protective strategies. Qualitative interviews were conducted with a sample of 24 parents of preschool-age children, purposefully selected to be diverse in gender, race/ethnicity, age, and personal experience with sexual abuse victimization. The findings support earlier research showing little congruence between perceptions of risk for the general population and perceptions of personal risk. The qualitative methodology provided some reasons for the discrepancy: comparisons parents make between themselves and other parents, characteristics of sexual abuse that affect perceptions, and the tendency of parents to blur the boundaries of sexual abuse with other forms of victimization. Parents identified strategies they used to protect their children from abuse and their underlying thoughts regarding protection. The exploratory results indicate the importance of understanding parents' cognitive processes in estimating risk and acting protectively and suggest further avenues for research.

Since child sexual abuse has been recognized as a social problem, the professional and research communities have devoted considerable effort to the development and implementation of education and prevention programs. Classroom-based, child-centered educational programs aimed at teaching children to recognize and respond appropriately to danger have been the primary focus of prevention efforts. To a lesser extent, parents have been targeted to receive information about sexual abuse and protective actions to take. Recently, however, there has been an increased call to focus more attention on parents' role in prevention (Reppucci, Jones, \& Cook, 1994; Wurtele \& MillerPerrin, 1992).

To date, the little research that has centered on parents' protective efforts has focused primarily on parents' feelings and behaviors in educating their children about abuse. In general, the research literature suggests that parents feel positively about educating their children, but their knowledge of sexual abuse is often limited and their efforts are not comprehensive (Elrod \& Rubin, 1993; Finkelhor, 1984; Wurtele, Kvaternick, \& Franklin, 1992). For example, conducting a telephone survey of parents with children in preschool, Elrod and Rubin (1993) found that parents wanted to be the primary educators of their children on sexual abuse topics, but the researchers found parents lacked knowledge in such areas as the prevalence of abuse. The survey also found that more than half of the parents planned to discuss some of the least threatening topics (e.g., lessons about strangers), and almost a quarter intended to discuss all the topics at some point.

In earlier research, Finkelhor (1984) studied parents of children age 6 to 14 in Boston and found $29 \%$ of parents reported they had had discussions with their children about sexual abuse. Of these, only $53 \%$ of discussions mentioned the possibility of abuse by an adult acquaintance and only $22 \%$ by a family member. Also, most parents believed age 9 was the optimal age for discussing sexual abuse, although many prevention professionals feel this is quite late. Concentrating on a younger population, Wurtele and Miller-Perrin (1987) found that fewer than half (47\%) of parents of kindergartners had discussed the topic of child sexual abuse with their children. More recently, $59 \%$ of the 375 parents of preschoolers studied by Wurtele et al. (1992) said they had discussed child sexual abuse with their children.

Author's Note: Thanks to Kathleen Faller for her comments on an earlier version of this manuscript.

CHILD MALTREATMENT, Vol. 1, No. 1, February 1996 53-64 (c) 1996 Sage Publications, Inc. 
Several reasons have been suggested as to why parents are reluctant to discuss sexual abuse. Finkelhor (1984) reports that some parents in his study did not feel that sexual abuse was a serious problem or they felt their own children were not at risk. Also, some parents had concerns about frightening their children or had difficulty discussing sexual abuse because of their discomfort talking about sexual topics. Wurtele et al. (1992) found that the main reasons parents gave for not discussing sexual abuse were that the need for discussion had not occurred to the parent or that the parent felt the child was too young for the discussion.

In summary, although most parents express an interest in and intent to discuss sexual abuse with their children, substantial percentages have not had these conversations. Furthermore, parents have demonstrated limited knowledge about the problem, and the topics they cover in their discussion are primarily restricted to less threatening topics, such as potential harm from strangers.

Recognizing the importance of parents as key players in the prevention of child sexual abuse, the current study was designed to examine parents' perceptions of child sexual abuse as a risk, their protective behaviors, and the influence of perception of risk on protective behavior. Theoretical concepts in the literature on risk perception and health behavior were used to guide the study.

To complement the attitudinal surveys that have been conducted on the topic of parents' attitudes and beliefs about sexual abuse and its prevention (e.g., Wurtele et al., 1992), the current study used a qualitative methodology to more fully explore parents' understanding of abuse. Recent researchers in the field of health behavior (e.g., Cleary, 1987) have suggested that an in-depth understanding of how individuals conceptualize a risk is critical to understanding their protective behavior.

\section{METHODOLOGY}

In general, qualitative methods are used to provide detailed descriptions and explanations of social phenomena and to reflect the point of view of informants. By limiting preconceived notions and highly structured questions, informants are able to describe their lives from their own, rather than the researchers', perspective. In the current study, qualitative methods were selected because the phenomena under study (i.e., parents' perceptions of risk of child sexual abuse and protective behaviors) are notyetwell understood. Child sexual abuse is not a well-defined risk (such as a childhood disease); it involves numerous potential scenarios and therefore can mean different things to different people. Also, behaviors to address the risk do not involve simple, one-time efforts (such as inoculation). Thus, the complex nature of the risk and attendant protective behaviors suggested that much could be learned by focusing the inquiry on the parents' point of view, understanding their conceptualization of the problem, and learning about their naturally occurring protective behaviors.

Semistructured interviews were conducted with parents to explore variation in parental perception of risk and protective behaviors. An interview guide was developed and pilot-tested with five parents. The final instrument consisted of several questions covering eight major areas: current risks facing children, the probability of risks, the meaning of child sexual abuse to the parents, personal experience with abuse, sources of information about abuse, cultural views of parenting, views of violence, and protective strategies.

Chicago-area parents with preschool-age children were the target sample for the study. The parent sample was limited to those with children in this age group because many parents begin to recognize, think about, and deal with risks to their children from the outside world when their children attend preschool. Because of the exploratory nature of the study, maximum variation sampling was used to deliberately select parents with a wide variety of life experiences and life circumstances. Community areas were selected based on census data determining variation in race/ethnicity and income level. After the five communities were identified, a day care information and referral service was contacted and asked to provide a listing of two preschools for each area (one to serve as a back-up if the first preschool declined to participate). In three communities, the first preschool contacted agreed to participate, and the second preschool was not contacted. In the fourth community area, the first declined to participate because most of its clients were primarily Spanish-speaking and would have trouble with the interview; the backup preschool agreed to participate. In the fifth community area, however, neither school participated. The schools did not give a reason; however, both were proprietary day care centers. As these were the only two preschools in that community, a different community was selected, and a preschool site was chosen based on a recommendation from a staff member at an already participating site.

At each site, directors were instrumental in identifying subjects for participation and making the initial contact with the subject. The strategy of maximum variation sampling begins with the selection of any people who fit the sample criteria, and sequential selection of additional subjects to achieve variation in 
key characteristics. Therefore, at early stages of sample selection, directors were asked to seek any volunteers among their parents. At later stages, special efforts were made to seek parents who had underrepresented characteristics. Consequently, fathers and young parents, who were missing from the sample in the early stages, were specifically recruited in the latter stages (the young parents were recruited from a separate social service program specifically serving teenage parents). Sample variation in sexual abuse history was also desired; however, the sample demonstrated variability on this dimension, and no special efforts were made to recruit subjects on this basis. The sampling procedure and its reliance on directors' knowledge of, and relationship with, parents likely produced a sample that was biased toward parents who were more involved in their child's care and who were more interested in safety issues than would be the case using random selection. After securing initial interest of subjects, the directors provided a list of potential subjects' names and phone numbers. The researcher contacted the parents, explained the study, and made arrangements for the interview. Directors stated that no parents refused to participate, and the researcher received no refusals when contacting parents.

The final sample consisted of 24 parents, including 19 women and 5 men; 14 blacks, 7 whites, and 3 white-Hispanics; 11 currently married parents and 13 who were currently single, separated, or divorced. None of the respondents were married to each other. The parents had between one and three children ranging in age from 2 months to 14 years. Parents occasionally described their feelings and behaviors regarding each of their children, but the focus of the interview was their preschool-age child. Thirteen of these children were boys and 15 were girls ( 4 parents had 2 children attending preschool at the time of the interview). Nine parents were employed (positions included paraprofessionals, clerical workers, and professionals), 5 were not employed ( 3 by choice) , 3 were in some type of school or training, and the employment status of 2 parents was unknown. Education level varied from less than high school to graduate training. Regarding sexual abuse history, 8 parents described an abusive incident before the age of $18 .^{1}$

The five preschools and teen parent center represented six community areas (although parents often lived in the same area, this was not always the case). These areas represented upper middle-class, middleclass, working-class, and lower-income neighborhoods. The centers themselves consisted of two private preschools, three community center preschools, and a teen parent program. The upper-income families were primarily found in the private schools, whereas middle- and lower-income parents were found in the community centers and the teen parent center.

The average length of each interview was $90 \mathrm{~min}$ utes, with a range of 1 to 2 hours. Most interviews took place in a private space at the day care center or teen parent center, although several took place in respondent homes or coffee shops. Prior to beginning the interview, subjects were informed of their rights as research subjects (e.g., voluntary nature of participation, confidentiality of information, $\$ 10$ remuneration), as well as the researcher's duty to report suspected incidents of abuse. Interviews were tape recorded for all but one case, in which the respondent objected.

Analysis of data was conducted concurrently with data collection to begin the identification of categories and explore linkages, as well as to inform ongoing sample selection and data collection. An initial coding scheme was developed based on the literature review, the conceptual framework, the research questions, and the findings from the pilot study. The constantcomparative method of coding was used, in which each subsequent unit of text is compared with those already coded to refine the coding rules (Glaser \& Strauss, 1967; Lincoln \& Guba, 1985). As difficulties in categorization arose, properties of the categories were examined. In some cases, the category was renamed to include the broader examples (e.g., risk factors such as drug use in family, family fighting, and uncommunicative families were renamed under the broader category of family dysfunction). In other cases, new, mutually exclusive categories were formed (e.g., in response to questions about protective behavior, several parents gave responses that instead discussed their actions if they learned their children had been abused; these actions were labeled "reactive behaviors" and were mutually exclusive of protective behaviors); or the next unit of data became a subcategory of the main category, with attendant explanation regarding its relationship to the main category (e.g., "assessing informal child care" was differentiated from "assessing formal child care," and both were types of protective behaviors).

The final coding scheme included major codes such as Risk, Probability, Victim Description, Beliefs, and Protection. Within these major coding categories, there were several secondary and sometimes tertiary codes. Although the first, and sometimes second, level of codes such as Risk and Probability were developed a priori, the more refined codes were derived and named as the interview transcripts 
were reviewed. When the coding scheme became final, each of the transcriptswas recoded based on the finalscheme.

To enhance the reliability of coding, a research assistant was hired to independently code the interview transcripts. The rate of agreement was $80 \%$, calculated as the ratio of agreements to the total number of possible units of coded text. Additional measures, suggested by Lincoln and Guba (1985), were used to enhance the trustworthiness of the study. These measures included checking data interpretation with respondents during the course of the interview and, in follow-up interviews with a subset of respondents, using a "peer de-briefer" to serve as a check on bias, and conducting negative case analysis (i.e., review of cases that did not fit the developing analysis and accounting for divergence in the developing theory).

\section{RESULTS}

\section{What Are Parents' Perceptions of Risk of Sexual Abuse?}

Parents were asked to describe their views about risk of sexual abuse for all children and also risk of sexual abuse for their own preschool children. Also, parents were asked whether they believed some children were at more risk than others, and if so, what characteristics or circumstances put some children at more risk than others.

Risk in the general population. In talking about the extent of the problem of child sexual abuse in the general population, parents were asked how "common" they thought the problem was; in addition, they were asked to provide a prevalence estimate (i.e., in a group of 100 girls/boys how many do you think have been sexually abused). Typical responses to the first question suggested parents thought that the problem was quite common: "I don't want to think that it's common, that it's happening every day to some child. But to be realistic, I believe it is." The quantitative prevalence estimates that parents gave for girls ranged from a low of $1 \%$ to a high of $90 \%$ for girls, with a mean estimate of $36 \%$ and a median of $30 \%$. The estimates given for boys ranged from $1 \%$ to a high of $60 \%$, with a mean estimate of $25 \%$ and a median of $18 \%$. Three parents felt unable to give a numeric estimate because they felt they did not have adequate knowledge about the problem.
Although most parents' estimates and accompanying rationales indicated they perceived abuse to be more common among girls, two parents thought child sexual abuse was more common among boys. In one case, the parent worked for an insurance firm that processed claims against the Catholic Church for child sexual abuse. She reported that, in these cases, the victims have typically been boys, and she theorized that boys were at greater risk because it was more natural and acceptable for a friendship to develop between a man and a young boy. Consequently, there was more opportunity for abuse to occur without raising suspicion. The second parent who felt boys were more commonly victimized said that she had known of several male victims but has found that boys are less inclined to talk about their abuse.

Personal risk for own children. Responses to the questions about risk for one's own child are found in Table 1. Of the 24 parents interviewed, only one parent viewed child sexual abuse as a major risk (i.e., overwhelming or immediate threat) facing her child. The family (mother and three children) was living with the mother's aunt, who has children who are "advanced." In part because of the perceived risk, the mother was planning to move her family out of the home within the week. She had also begun educating her own children about appropriate touching to avoid their victimization and to keep them from abusing other children.

Ten parents viewed sexual abuse as a moderate risk facing their children (moderate was defined as those who could conceptualize current circumstances in which their children might be at risk). For example, one mother stated there might be some risk "outside of the home maybe in some instances" and had taken several precautionary steps to increase her children's safety. Another mother said that she worried a little about the Catholic school her daughter would go to but "you have to take your chances, I think it's bad everywhere." A father replied, "I worry about it maybe in the sense that I can't be around her $100 \%$ of the time. You never know what happens in environments that you are not around and you can't control."

In contrast to those who viewed child sexual abuse as a moderate risk for their child, nine parents perceived it to be only a slight risk (defined as viewing their child as safe from sexual abuse at this point in time). The majority of these parents viewed their 
TABLE 1: Risk Perception for Own Child

\begin{tabular}{lcc}
\hline & ${\text { Number of } \text { Cases }^{\mathrm{a}}}^{\mathrm{a}}$ & Percentage $^{-}$ \\
\hline High risk $^{\mathrm{b}}$ & 1 & 4 \\
Moderate risk & 10 & 42 \\
Slight risk & 9 & 38 \\
Very slight/no risk & 4 & 17 \\
Total & 24 & 100 \\
\hline
\end{tabular}

a. Although four parents had more than one child of preschool age, each parent viewed both children at the same level or risk.

b. Categories of risk were assigned based on parents' descriptions of the current level of risk their child faced.

children at slight risk either because the people who were involved with their children were "beyond reproach" or because they felt they did not put their children in situations where abuse might occur. For others, the risk level seemed slight primarily because they felt their protective efforts were effective. One mother stated,

I'm not frightened for my children at this point but I'm real careful about who I leave them with. I'm not paranoid about who I leave them with but I'm careful. And I'm trying to empower them, what's appropriate behavior and what isn't, when they have a voice to say "no."

Although several parents implied that their children were at less risk than other children, four parents stated explicitly that they were concerned about the risk of child sexual abuse for other children, but not for their own. One mother gave two reasons why abuse was not a problem for her children: because the children's father lives with the family and because she has educated her children about abuse. She compared herself to a relative who has a daughter and male friends "in and out" and to other parents who "don't take the time to educate the children." Another mother did not worry about abuse mostly because she was teaching her children how to handle potential abuse situations if they were approached. She also made several statements indicating that she felt child sexual abuse happened to "others" (e.g., families less open and communicative, uneducated, Blacks, etc.). A third mother was not concerned because her child was a boy; she stated, "if he were a girl, I'd be more concerned." Finally, one mother offered two reasons: because "they're not really around anybody" who would abuse them and because if they were abused "they will tell me."

Parents' estimation of their own children's risk level was compared with the prevalence estimates they provided for the general population. For this purpose, parents were grouped in two categories: high/moderate versus slight/very slight, and these two groups were compared with the prevalence estimates provided. A
Mann-Whitney $U$-test was used to determine whether the two groups differed significantly in their prevalence estimates. Differences were nonsignificant for both estimates of girls $(U=44.5, p=.47)$ and boys ( $U=$ $46, p=.56)$. Thus, there appeared to be little relationship between prevalence estimates of child sexual abuse and perception of risk for one's own child.

Risk factors for sexual abuse. To ascertain parents' understanding of risk factors for sexual abuse, parents were asked whether they felt some children were at greater risk for sexual abuse than others. Most of the risk factors that parents mentioned focused on either victim or family characteristics. Victims' gender, age, and personality were the key individual-level risk factors. Girls were thought to be at more risk than boys, typically because parents more often heard about girls being victimized or because girls were perceived as weaker and more vulnerable. Younger children were considered to be at far greater risk, because they cannot defend themselves, because they are not as educated, and for the very young, because they cannot talk. There was some variation in beliefs about the type of personality that would increase risk. Some parents envisioned shy, introverted children with low self-esteem to be potential targets, whereas others suggested children who were open and friendly were more likely to be abused.

Discussion of family risk factors focused primarily on family behavior that put a child at risk, rather than descriptive characteristics. Several parents compared the supposed dysfunctional family to their own lifestyle; for example:

But I think it has a lot to do with parents, with the drug group, abuse is going on, alcoholism, a lot of strange men come into the home, or whatever, it just leaves your child open and vulnerable for anything to happen to him ... see I know my child would never be abused because she would come and tell me. I think kids get abused when their parents, they don't communicate with their parents. I think that leaves them open.

Other parents who talked about dysfunctional families as a risk factor described families that were always "partying"; parents who did not pay enough attention; families with combined problems of poverty, drugs, and alcohol; parents who "aren't there" for their children; and families in which there are strained relationships between the two parents or between the parents and children, as well as those that do not allow children to have a "voice."

In terms of descriptive characteristics, a boyfriend or stepfather in the household was mentioned by two parents as a risk factor. Although single-parent fami- 
lies were felt by some to be a risk factor, one parent thought that the greater risk in these families was due to the reduction in the number of natural caretakers, thus requiring more reliance on outsiders. Finally, families in which a parent or other family member had been abused and families living in high-rise public housing were thought to be at greater risk.

More revealing than the identification of risk factors, however, were the comments of the seven parents who felt all children were at equal risk of victimization. One parent, a father, made an important distinction; he felt the risk of approach is the same for all children, but the risk of completed abuse is dependent on the parents' efforts to instruct their child on how to handle the situation. In support of his stated beliefs, throughout the interview this father described numerous efforts on his part to educate his children about abuse.

The remaining six parents seemed hesitant to name risk factors, as if this implied that the victim was responsible (e.g., "I don't think no one really [is at risk], I think that, I can't really say, I guess no one asks to be bothered"). This attitude seemed particularly true for all four of the young mothers. The context of many of their statements described the similarities of rape and child sexual abuse and involved a discussion of "fault." One young mother, who had been raped by peers four years previously, best exemplified this tendency:

I know children hide stuff from their parents, because they're thinking "it's my fault" ... "I'm not going to tell her I'm sure she's going to blame me" . . . and people say "oh she's a fast child, she deserves to be abused." Even if you're a fast child, it doesn't, you don't deserve to let anybody mistreat yourself or your body.

Discussing risk, she continued, "I really don't think there's a risk. I think that anyone can be abused, a 30-year-old, a 40-year-old, a 2-year-old, a one-year-old, a newborn can be abused. But you shouldn't be."

To a lesser extent, the other young mothers seemed to be saying much the same thing. Another young mother, who had been a victim of sexual abuse at age 9, stated, "You know things happen to any, anybody's really at risk. You can't tell who the person is ... . anybody's at risk, you never know who it might happen to." The final two young mothers, who did not report any history of sexual abuse, made similar statements. One stated, "There's no particular look. No particular dress. It just happens." The other, again, talked about the similarities of rape and sexual abuse:

It's just, anyone could be. I guess rape and sexual abuse, I don't know if you can really call them differ- ent-rape is like, could be considered against your will but sexual abuse is really, could be considered against your will because for little kids they don't know. . . . But I guess it could still be called rape and I don't think they have any difference. There's no way that you look, because you can look normal and it can just happen.

While many of these statements are basically true (i.e., victims cannot be identified a priori by their appearance), the statements do suggest that some parents may have difficulty with the concept of risk as a probability of occurrence rather than as a condition attached to inherent blame. The statements are also troubling because they equate the belief that children are at equal risk with statements that sexual abuse "just happens," a belief that characterizes the risk as random and inevitable, and therefore, likely to affect parental inclination to take protective action. Finally, because these feelings seemed common to all four young mothers, it is possible that their responses are in part due to societal pressures they may feel about responsibility to avoid their own sexual assault.

\section{What Protective Strategies Do Parents Employ?}

Parents employed a variety of strategies to keep their children safe and to prevent child sexual abuse in particular. The number of protective behaviors ranged from 0 (one parent) to 5 (two parents), with a mean of 2.6 and a mode of 2 . Table 2 lists the various protective mechanisms parents reported. These strategies included basic elements of protective behavior (e.g., supervision) and protective strategies particularly targeted toward protection from child sexual abuse (e.g., educating the child about abuse). Some parents discussed several strategies; others described more minimal protective efforts.

Basic protection. The basic protection strategies parents used to protect their children from general danger as well as sexual abuse included providing supervision, developing a strong relationship, taking an interest in the child's life through questioning, and investigating and monitoring child care options.

Almost all parents made some statement about watching their children in general; however, only 11 parents spoke of supervision within the context of sexual abuse prevention. Although some efforts seemed fairly passive, "When she's playing I watch. Or my wife will watch. Or some responsible adult will watch"; others spoke of supervision at length, describing a variety of situations in which they supervise their children. A form of supervision more commonly used with older children but occasionally extended to the preschoolers was to limit activities. The most common limitation was the refusal to allow children to stay 
TABLE 2: Parents' Protective Behaviors

\begin{tabular}{lcc}
\hline & Behavior $^{2}$ & Percentage $^{\mathrm{a}}$ \\
\hline Basic protection & 12 & 50 \\
Develop relationship & 11 & 46 \\
Provide supervision & 6 & 25 \\
Ritual questioning & 4 & 17 \\
Limit activities & & \\
Sexual abuse-specific protection & 22 & 92 \\
Provide education & 6 & 25 \\
Look for/confront signs & 2 & 8 \\
Take dating precautions & & \\
\hline
\end{tabular}

a. Categories are not mutually exclusive; percentages do not sum to $100 \%$.

overnight with friends: "it seems the most thing that I end up doing is to keep them close to me more. I don't let them go to that person's house, I don't let them be very familiar with that person or that other person."

Twelve parents discussed some efforts to build a relationship with their child as part of their effort to protect against sexual abuse. In developing a close relationship, parents had three aims: They wanted their children to feel comfortable coming to them for help, they did not want their children to fall under the influence of others, and in some cases, they wanted to build their children's level of confidence, which might protect them from being targeted by a perpetrator (e.g., "like my daughter, I want her to have confidence in me and I think I'll always be there for her. So I don't think there'll be the need for her to go out and look for another mother-figure or fatherfigure, because we're there for her"). As implied, these efforts were made, in part, because parents thought children without a close relationship to their parents were at greater risk for abuse. In response to a somewhat related question, six parents described using ritual questioning about their child's day as a means of developing a relationship and checking for child sexual abuse or other trouble. Generally, these efforts included consistently asking the child about his or her interests, concerns, and feelings, as well as questioning the child in specific situations such as when picking the child up from day care or after another activity (e.g., "What did you do today?").

A further component of child protection was ensuring a child's safety when he or she was being cared for by others. In terms of informal child care, family members were typically most trusted, although two parents expressed some concerns about the trustworthiness of family members, and four others commented that although family members were more trustworthy than nonfamily members, they did not really feel sure about anybody. After family, parents usually used at least one of three mechanisms for developing trust: Seven parents said they relied on intuition (e.g., "just the feeling I get from them"), seven parents described assessing good parenting or lifestyle (e.g., churchgoers or those who act with "sensitivity" and "patience"), and three parents used repeated testing and interaction (e.g., "you have to go through a prolonged period of interacting with that person").

As a group, the parents in this sample were highly satisfied with their formal child care arrangements and, for the most part, had a great deal of trust in the child care centers. Parents demonstrated variation in the amount of thought given to trustworthiness. Some were relatively simplistic (e.g., "They have a very good reputation. I haven't heard of anything happening as far as child abuse or anything like that"). On the other hand, some parents distinguished themselves by being especially active in finding child care or by their ongoing monitoring of the center; yet they still voiced concerns that "you just never know."

Protection specific to child sexual abuse. In addition to general protective strategies that have been expanded to protect against child sexual abuse, some parents discussed strategies aimed specifically at sexual abuse. These strategies concentrated on identifying abuse at an early stage by checking for signs of abuse and talking with their children about safety. Also, two of the single parents reported that they took precautions when dating to protect their children from possible harm.

Six parents indicated that they looked specifically for signs of sexual abuse and confronted them by asking questions. One mother was highly observant at this point in time because she felt her children were currently in a high-risk living situation:

And I tell my son, I ask him, I say every night before we go to bed, like when I change his underwear and stuff, I ask him, I go through everybody in my whole house, I say, "Has such-and-such been messing with you or touching you?" I tell him the name of the private part and I asked him if they've been touching it. And he say, "no, no." As far as him being little, I don't know if he will tell me, if somebody might tell him, "Don't tell your mama, she'll whip you." So I don't know but so far I don't think so.

It was not possible to tell from the interviews who just looked for, and who was willing to confront, signs of abuse. The detail with which some parents, such as the mother quoted above, described their efforts suggested they would be willing to deal with indicators of abuse. In addition, a couple of parents discussed times when they were uncomfortable with child care providers and terminated those child care arrangements. 
On the other hand, one parent stated that she was always looking for signs of abuse, but at three points in the interview, she discussed situations in which she was initially suspicious that something inappropriate might have occurred, but she then dismissed the situation (e.g., "I'm sure it was nothing").

In terms of prevention education, nearly all parents gave some indication that they had talked with their children about safety, but there was significant variation in the content of the messages, the focus on sexual abuse specifically, and the sophistication with which the messages were delivered. Twenty-two parents identified at least one concept they taught their children; eight parents identified four or more messages. Nine parents, including all five fathers, provided two or fewer concepts they discussed with their children. Three of the fathers stated that they were more reliant on someone else, either their wives or the school, to educate their children about sexual abuse. For example:

No, I can't say I've even talked to her in terms of sexual abuse and what's OK for people to touch you and when it's OK. But at the same time, I've tried to be very open with her about her own body or boys' bodies. I think my wife will probably be better at that than I am. I think I would have to rely on probably some of the books that are out to help talk to kids about it. Just on my own I don't think I could do a very good job of it.

The two male exceptions to this reluctance included one father who seemed to be willing to engage in very specific discussions about sexual abuse, both with his preschool son and adolescent daughter. The second father who stated that he discussed sexual abuse with his daughter unfortunately was prompted to engage in this discussion because his daughter had been victimized; he said that prior to her victimization, it had never occurred to him to talk with her about abuse, but since her disclosure, they have had several discussions.

Table 3 provides a listing of the education messages that parents said they taught their children. The most frequent messages communicated to children involve appropriate touching, identification of private parts, telling, and actions to take if approached.

Thirteen parents discussed different types of touching, some using the labels such as "good and bad touching," but all conveying in some way that some parts of the body should not be touched by others. Ten parents had talked with their children and identified private body parts. Typically the identification of private body parts was coupled with messages about touching and boundaries. Lessons about appropriate touching were concrete and identified parts of the
TABLE 3: Parents' Educational Messages

\begin{tabular}{lcc}
\hline & Number Reporting & Percentage $^{\mathrm{a}}$ \\
\hline Appropriate touching & 13 & 54 \\
Telling & 11 & 46 \\
Private parts & 10 & 42 \\
Actions to take & 10 & 42 \\
Strangers & 9 & 38 \\
Boundaries & 8 & 33 \\
Depend on parent & 6 & 25 \\
Not child's fault & 4 & 17 \\
Sexual abuse definition & 2 & 8 \\
\hline
\end{tabular}

a. Categories are not mutually exclusive; percentages do not sum to $100 \%$.

body that should not be touched.

Occasionally, additional rules were added that parents or a doctor might be able to touch private parts if there is pain or injury, but only two parents discussed this detail. Messages about boundaries or body rights were more conceptual and linked to efforts to empower children that they can make decisions about their own body.

Eleven parents had instructed their children to tell about problems related to inappropriate touching, although the specificity of messages vary. For example, one mother stated, "I say, someone tries to mess with you and you're at day care, run and tell your teacher." Two mothers had instructed their children to ignore the threats of the abuser and to tell anyway, and another had identified a variety of people to tell.

In addition to encouraging their children to tell about the abuse or attempted abuse, some parents taught their children about what to do if an attempt was made. Role-play of potential bribe scenarios were described, as well as running away, saying no, and yelling. One mother was among the most comprehensive:

They should try to get to me if at all possible or get to some adult and tell somebody, make sure that you tell somebody that this had happened. And call me, they normally know where I am at all times, call me, call somebody in the family, if you can't get away and get to one of us. But walk away if you can, if they'll allow you to walk away, just walk away from them, tell them no, always say no, do that, but if they're a stranger or something and there's nothing you can do, then it's not your fault, we'll get help for you.

Another young mother lacked this level of sophistication but described making efforts to communicate complex ideas in a way her child could understand:

I just have to try to explain to her the best way I can. I really didn't know how to explain it to her, but I just want to get to her level to understand, "no" meaning "no.". . I I just try to talk to her but you know, when she gets old enough to really understand, about 6 or 7 , I'd then really tell her, "don't let this happen," you 
know "you tell him no and if a boy do something, pull you in the corner, you tell him no." You know I just talk to her. But she be telling me that a boy pushed her in a corner and hit her and I'm like, "you tell your teacher but that's not what I'm talking about."

Messages about strangers were fairly common. Nine parents conveyed that children should not talk to, or go anywhere with, strangers, even if the stranger offers the children something. Others go further and suggest that strangers will try to hurt them or will take them away so that the children will never see their parents again.

In answering questions about preventive and protective behavior, some parents responded in ways that are not normally considered to be either preventive or protective. Three parents confused these concepts with reactive behavior. These parents talked instead about the actions they would take after finding out about the abuse; threats to the abuser dominated the discussion. Again suggesting some conceptual confusion, several other parents confused a child's ability to disclose abuse that has occurred with his or her ability to prevent abuse. Also describing not specifically protective actions, four parents implied that leading a healthy lifestyle (e.g., involvement in activities) and a positive outlook were components of protective behaviors. These parents felt a strong necessity to guide their children to avoid bad influences that can lead them into danger or trouble. Although these suggestions were not specifically or explicitly related to child sexual abuse, eight parents talked in terms of providing positive influences for children and guidance to keep them safe. For example, one mother stated:

I've always believed in talking because, talking to your children, and giving them, you have a voice that paves the road. And if you pave the road for them, then it's easier for them to travel the right way and not to go off and go to the wrong way. Because it you don't help them, help pave the road then it's easy, if there's no way to follow, then it's easy to go off the wrong way. If you start a way for them to follow, and it's the right way, then it helps them to go the right way.

Finally, several parents attributed self-protective abilities to their children that may or may not be appropriate. Comments that the child "knows" about abuse, that "he'll come tell me, he tells me everything," and the child "knows what to do," were not rare; six parents expressed such confidence. Certainly children have some capacity to learn information about child sexual abuse and to be encouraged to disclose abuse. Often the individual child characteristics (e.g., talkativeness, intelligence) or general views of children (e.g., highly intuitive), however, seemed to be factors leading to parents' confidence. For example, one parent stated,
If my child doesn't want to be around you or touch you, then evidently there's something, it's a problem, because most kids know. A child could tell before an adult can, who an abuser is or whatever because it just seems like they have these feelings, when a child doesn't want to be around you, I feel that there has to be something wrong.

Another parent's child had only a little education in school and some reinforcement from her, but the parent stated,

And he knows a bad touch from a good touch. Kids they know, he knows. And I talk to him and let him know, "don't let anybody touch you there or give you any type of special hugs" or something out of that nature so he knows, he knows.

One other mother was one of the clearest in saying that her children were not at risk for abuse, in part because she felt her strategies were effective. However, here she discussed a very limited scenario:

They already know, I mean the 2-year-old, of course doesn't know anything, he doesn't understand and I wouldn't even try to talk to him about it. But the $4 \frac{1}{2}$-year-old, yeah. So, no, I don't really worry about it because I think that he would just run away from a person. I said, "even if the person offers you all the Ninja turtles, you would love to touch him in his private parts, what would you do?" "I'd run away." So he knows basically.

One father also sounds naive when he says about his preschool-age daughter,

She's pretty smart about it. She says, "I'll just go and scream 'help' if somebody tries to grab me." I said, "OK, go ahead and do that." And she's got things pretty well down. She knows her phone number and her address.

Three parents explicitly focused on children's inability to protect themselves. One mother generally discussed children's vulnerability to victimization and stated, "So I'm careful about all these things because they don't know and they trust these adults." A father focused on young children's limited understanding, which prevents them from adequately assessing potentially dangerous situations:

A 4-year-old child doesn't understand why a parent yells at them, doesn't understand why they're being beaten by their parents, doesn't understand why the parents are doing what they're doing to their bodies. They have no capacity to understand. It's not there yet.

Finally, the third parent was asked, in a followup interview, about parents' confidence in the selfprotective abilities of their children. She was highly 
resistant to the idea that children can easily learn to effectively apply prevention education. She recalled a television show in which children whose parents felt they had been well-educated about abuse prevention were led off by individuals involved in the project to test children's abilities. Also, she commented that children frequently need to be reminded even about the most mundane child activities (e.g., picking up toys).

\section{DISCUSSION}

\section{Risk Perception}

The tendency to view one's self at lower risk than others has been documented for several other types of risk (Perloff, 1983; Perloff \& Fetzer, 1986; Weinstein, 1980) and typically involves a "downward comparison" (Wills, 1981) with one who is perceived to be less fortunate. In this study, the tendency appears to exist in tandem with a tendency to identify specific domains in which parents believe themselves or their children to be at less risk than others: Parents identify risk factors that do not exist in their children's life (e.g., child is a boy, child lives in two-parent household, neither of child's parents were abused as children) and parents believe themselves to be more protective than others (e.g., parent does not leave child with a lot of people, parent always knows whereabouts of child, parent has educated the child). Furthermore, although parents exhibit some understanding of risk factors (i.e., epidemiological studies find female children are at greater risk, abusers frequently do have histories of victimization), it is the simplistic manner in which parents consider risk factors that may lead to errors in risk assessment. For example, statistically lower risk for boys as a group does not eliminate the possibility of victimization to one's own child.

In addition to variations in prevalence estimates and perceived risk factors, parents' statements also demonstrated differing conceptualizations of child sexual abuse in other aspects. This finding is important because other research has consistently documented that perception is not consistent across risks and that certain characteristics of a hazard influence whether it is perceived as risky (e.g., Slovic, Fischhoff, \& Lichtenstein, 1982; Weinstein, 1989). Review of parents' statements suggests some of the hazard characteristics found by Slovic et al. (1982) to increase risk perception (e.g., risks that are capable of affecting one's self, equitably distributed, uncontrollable, and difficult to reduce) were clearly evident in parents' thoughts about sexual abuse. I have already discussed the differences among parents as to whether the risk of child sexual abuse affects their children. Almost without exception, they think it is much less likely to happen to their children than to other children, although parents varied in the strength of these feelings. There is also ample evidence in the findings that most did not view risk as equitably distributed; only seven parents felt all children were at equal risk whereas most identified factors that increased a child's risk. Finally, although generally parents felt child sexual abuse to be out of their control and to be difficult to reduce, these views were not unanimous. A few parents felt some control over the risk, and some felt capable of reducing the personal risk level (through education and supervision of their children).

\section{Relationship Between \\ Perception and Behavior}

Because the aim of the study was to develop an understanding of parents' views rather than to test hypotheses about relationships, the focus of this article is in describing how this group of parents perceives and responds to the threat of child sexual abuse. Judgments about the adequacy or effectiveness of parents' efforts would be inappropriate. A few parents, however, distinguished themselves, and I will discuss briefly what their stories suggest about the relationship of perception and behavior.

Only one parent in the sample viewed her child at high risk, and her protective efforts appeared to be fairly comprehensive. Moreover, she was taking action to move her family out of an environment she felt was threatening to her children's safety. Thus, her story provides some support that high levels of risk perception induce parents to take protective behavior.

One mother, raising three boys in a dangerous public housing project, appeared heroic in her efforts to protect her children from child sexual abuse and 
the chronic, visible and immediate threats facing her family. Although she currently viewed her own children at moderate risk for sexual abuse, this mother viewed sexual abuse as a serious problem ( $90 \%$ prevalence rate), was quite knowledgeable about child sexual abuse, had taken efforts to educate herself, and referred to her own childhood victimization as a catalyst for her protective efforts toward her boys. Thus, despite both current and historically difficult living conditions, this mother has made the protection of her children a high priority in her life.

As noted in the results, three parents who were among the more protective discussed children's general inability to protect themselves from abuse. Their views of children's abilities did not preclude them from educating their children about abuse; they appeared quite diligent in their educational efforts. Instead, they proclaimed the need for repeated lessons and the formation of habits of safety. Their discussions suggest that views of children's capacities may be an important variable leading to protective behavior. Also, all three of these parents viewed their own children to be at moderate risk for abuse.

Among the least protective parents was one teenage mother who viewed her son at slight risk for abuse and who reported engaging in no protective behaviors. This mother was living with her own mother, whom she reported had primary responsibility for the care of her son. Also, during the course of the interview, this mother discussed many concerns in her own life as a teenager, and she also appeared to be actively recovering from a sexual assault that had occurred 4 years previously. These circumstances in her life suggest reasons why she may currently not perceive possible risk in her son's life or be engaged in protective activity.

In terms of protectiveness, there were no consistent findings along demographic lines. Although some of the fathers were less involved in protection, at least one father was among the most protective parents. Similarly, although one teenage parent was the least protective, another was among the most. Neither race/ethnicity nor indicators of economic status appeared to be related to the extent of protective behavior. Instead, the findings emphasize that the life circumstances of parents, including competing concerns, victimization history, and beliefs about children, may affect perception and behavior. Here too, however, the influence appears complex. For example, although one parent was able to use her victimization experience to help her protect her children, another younger and more recently victimized parent seemed unable at this point to recognize this possible threat to her child.
It is noteworthy that at times parents expressed confusion about two of the key variables: risk and protective behavior. I am referring to parents' confusion of risk factors with elements of blame and confusion of reactive with protective behavior. It is possible that parents can and do think in terms of risk and protection but do not associate the labels risk or protection with their thoughts. For example, although seven parents stated that all children were at equal risk, they provided higher prevalence estimates for girls than boys. Thus, they implicitly recognized risk factors, even though they did not explicitly enumerate them. Another possibility is that parents can and do think in probabilistic terms and recognize protective actions to take generally, but do not view child sexual abuse as a hazard that they think about in these terms (i.e., a hazard that they are able to prevent). Finally, it is possible that those parents demonstrating difficulty with these concepts may have either a temporary or long-term inability to think in probabilistic terms or take protective action. For instance, a recent victimization may temporarily divert internal resources to cope with the victimization rather than to assess and attend to the possibility of a child's victimization. Or individuals living in highly stressful situations may be unable to attend to the risk of sexual abuse given other more visible and immediate risks. The study's scope does not provide a strong explanation for parents' difficulties in discussing these concepts. More indepth research on these two concepts in smaller more homogenous groups (e.g., teenage mothers) may clarify the meanings of these terms for members of these specific groups.

\section{CONCLUSION}

This study described the perceptions of a small number of parents regarding the risk of child sexual abuse. It explored possible reasons for the commonly found difference between perceptions of general vulnerability (i.e., risk to others) and personal vulnerability (i.e., risk to one's own child), it identified differences in the way these parents thought about child sexual abuse, and it examined how parents described their efforts to protect their children from sexual abuse. The usefulness of the study is in its exploratory nature and its suggestions for further avenues of investigation. Although sample variability was obtained, there was no effort to be representative of the population. Hence, generalization of the findings is not appropriate. Moreover, the study's reliance on self-report, although necessary to construct parents' understanding of risk and protection, might limit the validity of the findings if parents provided socially desirable responses rather than honest answers. 
This article has suggested that inappropriate comparisons and a misuse of knowledge of risk factors has contributed to the gap between acknowledgment of the problem of sexual abuse and perception of personal risk. Some of the difference between societal perception and personal perception, however, may be due to parents engaging in protective behaviors. It seems important to distinguish between parents who view their children at lower risk because they are taking protective action and those who view their children at lower risk because they are making inappropriate comparisons between themselves and other parents. Prevention efforts aimed at the first group would need to encourage parents to continue their efforts while avoiding a false sense of security. Efforts targeted toward the second group would need to continue to challenge stereotypes and to convey information on risk factors that would avoid misinterpretation.

The extent to which differing conceptualizations of abuse affect risk perceptions requires further study with a larger and more representative sample. Three tendencies in particular suggest promising avenues for investigation. Parents' feelings of control over sexual abuse, parents' tendency to expand the problem of child sexual abuse to include other forms of violence and maltreatment, and the extent to which parents believed themselves to engage in protective behavior all appeared to have some effect on parents' perceptions of risk. More research on these and other factors would help to clarify the influences on risk perception.

Also, this study has suggested possible influences, other than perception of risk, on protective behavior. Key among these are parents' difficulties in thinking in a protective manner, beliefs regarding the child's capabilities for self-protection, a history of victimization, access to social support or assistance with child care, and cultural influences such as fathers' tendencies to defer protective actions to mothers. Each of these requires further exploration to determine the extent to which they have an influence, and under what circumstances.

\section{NOTE}

1. The incidents described included two incidents of child rape, one incident of peer rape by multiple perpetrators, two incidents of fondling by cousins, one incident of fondling by a baby-sitter, one incident of inappropriate advances by a supervisor, and one incident of fondling by an older peer.

\section{REFERENCES}

Cleary, P. (1987). Why people take precautions against health risks. In N. D. Weinstein (Ed.), Taking care: Understanding and encouraging self-protective behavior. New York: Cambridge University Press.

Elrod, J. M., \& Rubin, R. H. (1993). Parental involvement in sexual abuse prevention education. Child Abuse and Neglect, 17(4), $527=538$.

Finkelhor, D. (1984). Child sexual abuse: New theory and research. New York: Free Press.

Glaser, B. G., \& Strauss, A. L. (1967). The discovery of grounded theory. Chicago: Aldine.

Lincoln, Y. S., \& Guba, E. G. (1985). Naturalistic inquiry. Newbury Park, CA: Sage.

Perloff, L. S. (1983). Perceptions of vulnerability to victimization. Journal of Social Issues, 39, 41-61.

Perloff, L. S., \& Fetzer, B. K. (1986). Self-other judgments and perceived vulnerability to victimization. Journal of Personality and Social Psychology, 50(3), 502-510.

Reppucci, N. D., Jones, L. M., \& Cook, S. L. (1994). Involving parents in child sexual abuse prevention programs. Journal of Child and Family Studies, 3(2), 137-142.

Slovic, P., Fischhoff, B., \& Lichtenstein, S. (1982). Facts versus fears: Understanding perceived risk. In D. Kahneman, P. Slovic, \& A. Tversky (Eds.), Judgment under uncertainty: Heuristics and biases. New York: Cambridge University Press.

Weinstein, N. D. (1980). Unrealistic optimism about future life events. Journal of Personality and Social Psychology, 39, 806-820.

Weinstein, N. D. (1989). Effects of personal experience on selfprotective behavior. Psychological Bulletin, 105(10), 31-50.

Wills, T. A. (1981). Downward comparison principles in social psychology. Psychological Bulletin, 90, 245-271.

Wurtele, S. K., Kvaternick, M., \& Franklin, C. F. (1992). Sexual abuse prevention for preschoolers: A survey of parents' behaviors, attitudes, and beliefs. Journal of Child Sexual Abuse, 1(1), 113-128.

Wurtele, S. K., \& Miller-Perrin, C. L. (1987). An evaluation of side effects associated with participation in a child sexual abuse prevention program. Journal of School Health, 57, 228-231.

Wurtele, S. K., \& Miller-Perrin, C. L. (1992). Preventing child sexual abuse: Sharing the responsibility. Lincoln: University of Nebraska Press.

Mary Elizabeth Collins, Ph.D., post-doctoral research fellow, University of Michigan School of Social Work. Comments and requests for reprints should be sent to the author at University of Michigan, Social Work Center Building, 1015 E. Huron, Ann Arbor, MI 48105. 